\title{
(2) OPEN ACCESS \\ Right paraduodenal hernia with extensive bowel gangrene treated with staged surgery: a Bogota bag followed by resection in a low-resource setting
}

\author{
Vijay Anand Ismavel (ㅇ, ', Moloti Kichu, ${ }^{2}$ David Paul Hechhula, ${ }^{3}$ Rebecca Yanadi ${ }^{4}$
}

'Department of Surgery, Makunda Christian Leprosy and General Hospital, Karimganj, India

${ }^{2}$ Department of General Surgery, Makunda Christian Leprosy and General Hospital, Karimganj, India

${ }^{3}$ Department of Anesthesia, Makunda Christian Leprosy and General Hospital, Karimganj, India

${ }^{4}$ Department of Anatomy, Makunda Christian Leprosy and General Hospital, Karimganj, India

Correspondence to

Dr Vijay Anand Ismavel; ivijayanand@yahoo.in

Accepted 6 April 2021

Check for updates

(c) BMJ Publishing Group Limited 2021. Re-use permitted under CC BY-NC. No commercial re-use. See rights and permissions. Published by BMJ.

To cite: Ismavel VA, Kichu M, Hechhula DP, et al. BMJ Case Rep 2021;14:e239250. doi:10.1136/bcr-2020239250

\section{SUMMARY}

We report a case of right paraduodenal hernia with strangulation of almost the entire small bowel at presentation. Since resection of all bowel of doubtful viability would have resulted in too little residual length to sustain life, a Bogota bag was fashioned using transparent plastic material from an urine drainage bag and the patient monitored intensively for 18 hours. At re-laparotomy, clear demarcation lines had formed with adequate length of viable bowel $(100 \mathrm{~cm})$ and resection with anastomosis was done with a good outcome on follow-up, 9 months after surgery. Our description of a rare cause of strangulated intestinal obstruction and a novel method of maximising length of viable bowel is reported for its successful outcome in a low-resource setting.

\section{BACKGROUND}

Right paraduodenal hernia $(\mathrm{PDH})$ is uncommon and difficult to diagnose preoperatively without access to high technology diagnostic services. When faced with extensive bowel ischaemia, the surgeon is faced with a dilemma of resection of all definitive or suspected gangrenous bowel leading to short-gut syndrome and its sequelae or leaving behind potentially gangrenous bowel with risks of rupture and sepsis. This is especially true when the patient and hospital are in a low-resource setting without access to high technology or expensive treatment modalities. We report a case of acute extensive small bowel strangulation with ischaemia treated by staged surgery using a Bogota bag where there was partial recovery leading to adequate length of bowel and a successful outcome.

\section{CASE PRESENTATION}

A 23-year-old man from a village $15 \mathrm{~km}$ away presented to our remote rural secondary level hospital with acute onset of intolerable abdominal pain and vomiting 2 hours prior to presentation in casualty. He was working as a security guard in a large city in south India, $3500 \mathrm{~km}$ away and was at home after being laid off due to COVID19. He had no history of a similar episode in the past or previous history of abdominal surgery. Physical examination revealed a tense abdomen with palpable bowel loops. At presentation, he was stable with a pulse rate of $70 \mathrm{bpm}$, blood pressure of $100 / 60 \mathrm{~mm} \mathrm{Hg}$, oxygen saturation of $98 \%$ and temperature of $99.2^{\circ} \mathrm{F}$.

\section{INVESTIGATIONS}

White blood count $18.0 \times 10^{9} / \mathrm{L}$, haemoglobin (Hb) $159 \mathrm{~g} / \mathrm{L}$, hematocrit 46\% and X-ray abdomen erect revealed multiple air-fluid level. Ultrasound abdomen showed dilated bowel loops with free fluid. Serum creatinine was $1.9 \mathrm{mg} / \mathrm{dL}$.

\section{DIFFERENTIAL DIAGNOSIS}

The initial presentation and the persistent severe pain with the clinical findings of a tense abdomen with palpable bowel loops and worsening vital signs suggested bowel strangulation or acute ischaemia. There was no external hernia visible and the possibilities included internal hernias, midgut volvulus, superior mesenteric arterial occlusion, intussusception and entrapment in bands and adhesions. Since the hospital had no access to CT or MRI scans, the diagnosis could only be confirmed through an exploratory laparotomy.

\section{TREATMENT}

The patient was kept fasting, a nasogastric tube was inserted and aspirated, he was started on antibiotics and intravenous fluids, and he was being prepared for surgery after consent, about 4 hours after admission he suddenly became restless and tachypnoeic, and he had an unrecordable blood pressure. He was given $3 \mathrm{~L}$ of fluids and started on norepinephrine and taken for emergency surgery with a pulse rate of $160 / \mathrm{min}$.

The patient underwent exploratory laparotomy under general anaesthesia with 3-minute preoxygenation followed by lignocaine $60 \mathrm{mg}$ intravenously, ketamine $100 \mathrm{mg}$ intravenously with glycopyrrolate $0.2 \mathrm{mg}$ intravenously for induction. No anaesthetic gases were used as the patient was having a low blood pressure and was on inotropic support with dopamine at $10 \mathrm{mcg} / \mathrm{kg} / \mathrm{min}$. Succinyl choline $100 \mathrm{mg}$ was given for muscle relaxation and rapid sequence intubation was done. One hundred per cent fractional inspired oxygen was given during intubation, entire surgery and immediate postoperative period. Intraoperative non-invasive blood pressure, oxygen saturation, end-tidal carbon dioxide, ECG, urine output and temperature monitoring were done. Intraoperative findings showed that almost the entire small bowel $(20 \mathrm{~cm}$ from the duodenojejunal flexure upto $30 \mathrm{~cm}$ from the ileocaecal junction) was trapped inside a right $\mathrm{PDH}$ (figure 1). The herniated bowel was reduced and the edge of the mouth of the sac was slit anteriorly between the inferior mesenteric vein and the 


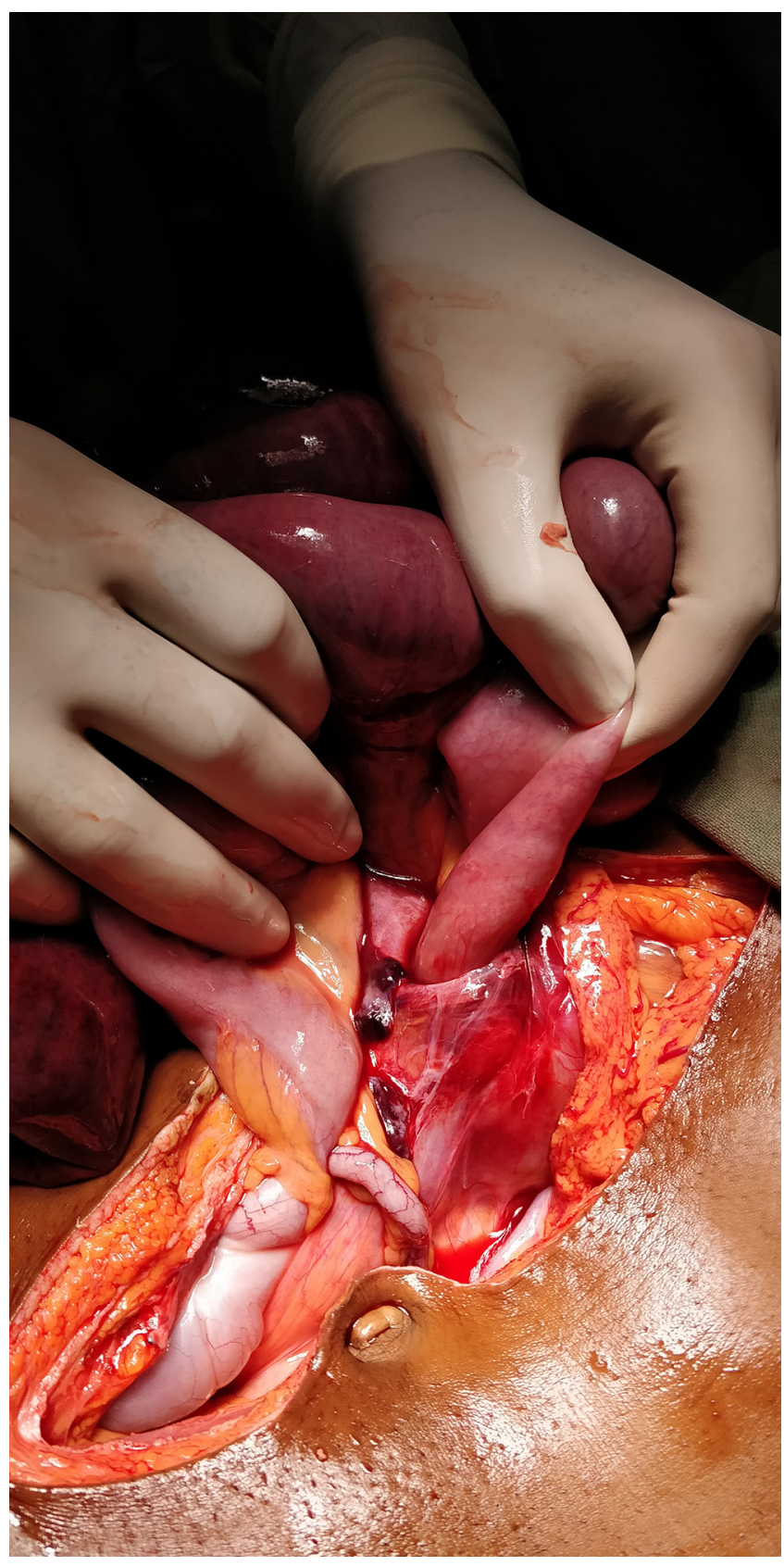

Figure 1 Small bowel being reduced from the right paraduodenal hernia.

superior mesenteric artery to prevent re-occurrence. Due to limited space within the sac and the bowel with its mesentery being compressed by the sharp edges of the sac opening, almost all the small bowel within the sac was dusky with no peristalsis and absent mesenteric pulsations. The bowel was observed for $45 \mathrm{~min}$, but there was no change; additional time was taken as the length of ischaemic bowel was extensive. Since resecting the entire unhealthy bowel would leave too little bowel for survival, it was decided to wait for upto 24 hours to see whether some of the bowel would recover.

Since it was not possible to easily reduce the distended bowel into the abdomen, temporary abdominal closure was done using a 'Bogota bag' created using plastic material from a urine drainage bag with the edge of the bag sutured to the linea alba around the wound. The bowel could be visually assessed through the transparent Bogota bag (figure 2).
Postoperatively, continuous monitoring of ECG, oxygen saturation, temperature, non-invasive blood pressure, end-tidal carbon dioxide, central venous pressure and urine output was done. In the initial 12-hour period, the patient showed signs of improvement in blood pressure and urine output. The colour of the bowel and blood gas analysis did not show significant change compared with the preoperative status. Eight litres of crystalloids were given during the 12 hours and dopamine infusion was tapered to $5 \mathrm{mcg} / \mathrm{kg} / \mathrm{min}$ over this period. Over the following 6 hours, there was no improvement in acidosis, $0.25 \mathrm{~L}$ of dark red blood was collected in the abdominal drain, $\mathrm{Hb}$ dropped from $130 \mathrm{~g} / \mathrm{L}$ to $100 \mathrm{~g} / \mathrm{L}$ and there was a drop in urine output and blood pressure requiring additional crystalloid infusion with one unit of whole blood and increased infusion rate of dopamine. The colour of the bowel observed through the Bogota bag, which had initially showed some improvement, became darker.

In view of the deteriorating condition, it was decided to re-operate 18 hours after the first surgery. When the bowel was exposed and examined, it was found that there was a much clearer demarcation between viable and non-viable bowel and the length of viable bowel was now about $40 \mathrm{~cm}$ from duodenojejunal flexure and $60 \mathrm{~cm}$ from the ileocaecal junction. Resection and end-to-end hand-sewn anastomosis was done on healthy bowel with bleeding edges using interrupted 3-0 polyglactin sutures. During the initial course of management, antibiotics were started with ceftriaxone and metronidazole and this was changed to piperacillin and tazobactam and finally to meropenem.

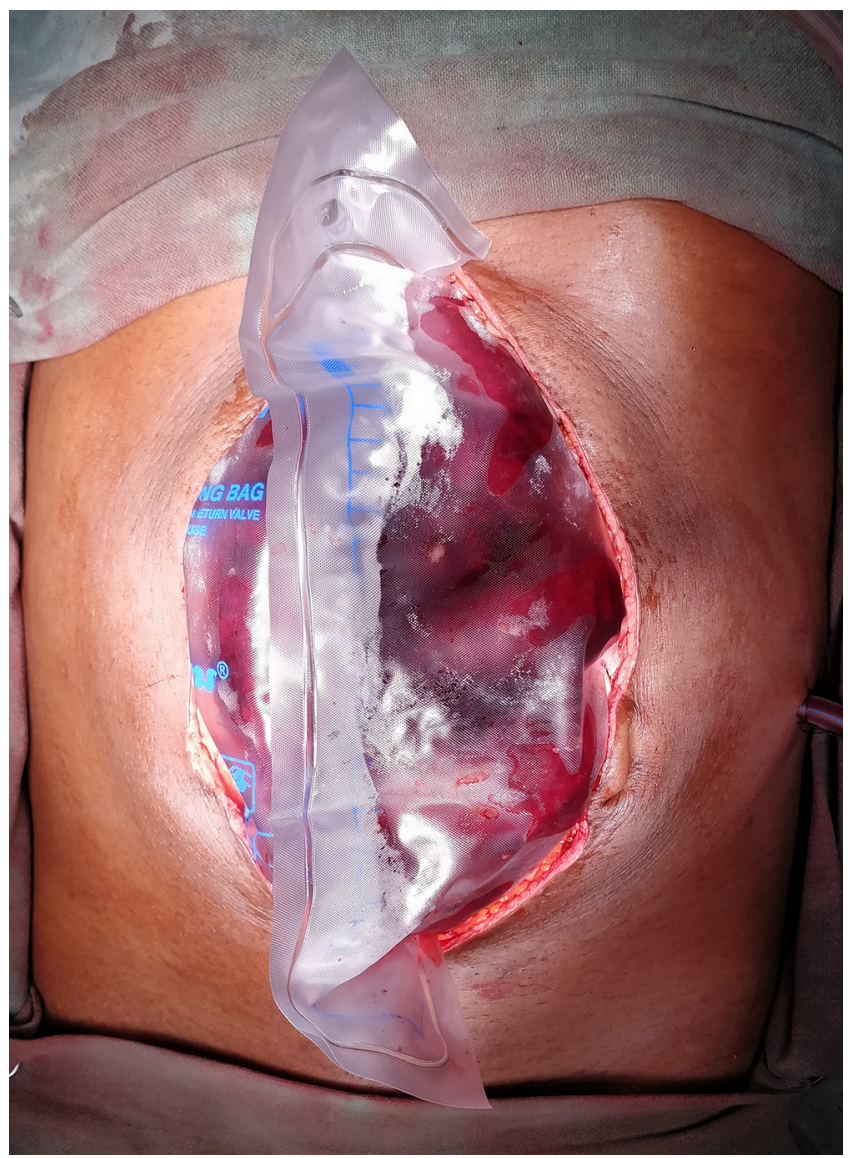

Figure 2 Bowel inside the 'Bogota bag' fashioned from plastic material obtained from a sterile urine drainage bag. 


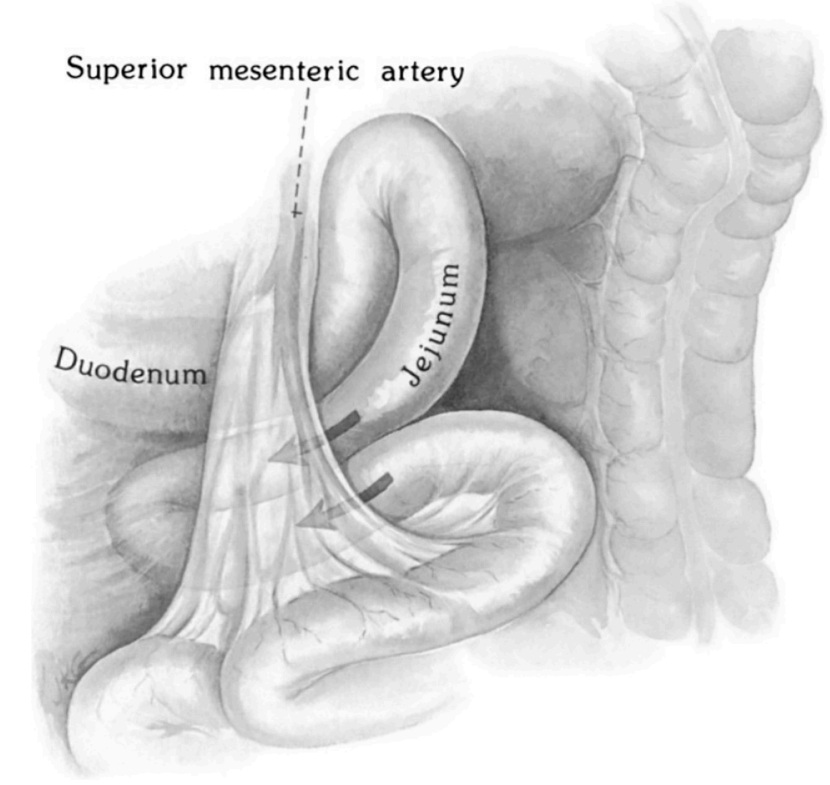

Figure 3 Anatomy of right paraduodenal hernia, showing bowel entering the fossa of Waldeyer with the superior mesenteric vessels along the medial border of the opening. (Reprinted by permission from Copyright Clearance Center: Springer Nature eBook: Dynamic Radiology of the Abdomen, 5th edition 2005, Morton E Myers, Internal Abdominal Hernias, 715; ISBN 978-0-387-21804-5).

The patient had an uneventful postoperative recovery, his serum creatinine recovered to $0.7 \mathrm{mg} / \mathrm{dL}$ and he was discharged on the 10th postoperative day following the passage of semisolid stools.

\section{OUTCOME AND FOLLOW-UP}

The patient recovered completely and reported passing normal stools with a weight gain of $7 \mathrm{~kg}$-from $44 \mathrm{~kg}$ at the time of discharge to $51 \mathrm{~kg}$ at 9 months. He was doing well but had not yet found a new job because of the COVID-19 crisis.

\section{DISCUSSION}

Internal hernias are a rare and potentially life-threatening condition with an incidence of $0.2 \%-0.9 \%$ among all cases of bowel obstruction. ${ }^{1-3}$ Approximately $53 \%$ of reported cases of internal hernias are PDH. PDHs occur due to defects in the reduction and rotation of the developing midgut. In their theories, both Moynihan and Andrews say that PDH is caused by 'physiological adhesions' arising during return of the bowel back to the abdomen and fusion of the common dorsal mesentery with the posterior abdominal wall forming fusion folds and fossae. $\mathrm{PDH}$ may be associated with malrotation of the gut and is more common in males $(\mathrm{M}: \mathrm{F}=3: 1) .{ }^{4}$ Depending on the direction in which the bowel herniates, PDH can be divided into left or right, of which right $\mathrm{PDH}$ is rarer than left $\mathrm{PDH}$ (right:left=1:3). Right PDHs are more prone to strangulation. ${ }^{5}$ They are caused by herniation of bowel into the fossa of Waldeyer, an opening that lies in the mesocolon with the inferior mesenteric vein to the left posteriorly and the superior mesenteric artery to the right anteriorly (figure 3). Bowel herniates into the retroperitoneal space and is drawn in by peristalsis. As with all herniae, obstruction and strangulation depend on the size of the opening, amount and type of contents, edge of the sac and elapsed time. In addition, strangulation can also occur in the non-herniated proximal jejunum due to torsion of the bowel as it enters the sac.
The diagnosis of PDH can be confirmed preoperatively using multi-detector CT scan with reconstruction in different planes. This modality was not available at the hospital, the nearest CT machine being $30 \mathrm{~km}$ away and the patient not fit for transportation.

Many centres have reported successful management of PDH laparoscopically, ${ }^{6}$ more easily performed for left sided $\mathrm{PDH}$. This option is not possible in an emergency setting with ischaemic bowel.

Any abrupt interruption or diminution of blood flow to the intestine leads to acute mesenteric ischaemia (AMI). ${ }^{7}$ Although most cases of AMI are caused by arterial embolism, arterial thrombosis, venous thrombosis or non-occlusive mesenteric ischaemia, a similar pathophysiology occurs during strangulation when mesenteric vessels are occluded by external pressure. The classic picture of AMI involves severe unrelenting abdominal pain with a paucity of abdominal examination findings. Excessive third space fluid loss leads to tachycardia, tachypnoea and circulatory collapse. These findings were found in our case.

Assessment of viability of ischaemic bowel is usually based on intraoperative examination. This could be deceptive as it is possible that some bowel may appear ischaemic due to arterial spasm or venous insufficiency and could resolve over time. When a critical length of bowel is involved, it is important to be sure that potentially viable bowel is not resected. To objectively decide on the length of resection, several innovative technologies have been studied in the past, including pulse oximetry, polarographic measurement of tissue oxygen tension, spectrophotometry, intravital microscopy, Doppler ultrasound, hydrogen gas clearance, radioisotope studies, fluorescence studies, infrared imaging, laser doppler flowmetry, bowel wall contractility measurements, $\mathrm{pH}$ measurements, microdialysis and assessment of electrical properties. Although several of these methods have been evaluated, none of them have met the requirements for reliable clinical application. ${ }^{8}$

The Bogota bag was a plastic bag first used by Borraez Goana of Bogota. ${ }^{9}$ Colombia and it has been used successfully for indications such as situations where early reoperation is necessary, to prevent abdominal compartment syndrome, for the treatment of gastroschisis in neonates, ${ }^{10}$ for the treatment of secondary or tertiary peritonitis and for the treatment of missing portions of the abdominal wall. In this case, it was decided to wait for some time to see whether more viable bowel could be salvaged. Since reducing all the bowel without decompression could produce an abdominal compartment syndrome, a Bogota bag was fashioned using plastic material from a sterile urine drainage bag. It was also thought that since the material of the bag was transparent, it would be possible to monitor bowel appearance through the bag. The authors think that this is the first instance of the use of the Bogota bag for a similar situation.

In adult patients with small bowel syndrome, small bowel length of less than $100 \mathrm{~cm}$ is highly predictive of permanent intestinal failure. ${ }^{11}$ The presence of terminal ileum and colon in continuity enhances survival probability. The hospital where the patient was treated is a remote rural hospital focused on providing high quality care at low cost to the poor. This patient would not have survived a major bowel loss requiring small bowel transplant or liver transplant. Total parenteral nutrition would also be beyond the scope of treatment as the cost would have been prohibitive.

The splanchnic circulation is governed by intrinsic (metabolic and myogenic) and extrinsic (neural and humoral) regulatory mechanisms. ${ }^{12}$ Adaptive changes in this circulation are based on amount of oxygen delivery to tissue rather than blood flow. An 
acute decrease in perfusion pressure due to ischaemia is compensated by reduction in arteriolar resistance thereby maintaining splanchnic blood flow. There is significant redundancy built in, requiring only $20 \%$ of mesenteric capillaries to remain open to maintain normal oxygen consumption. However, when blood flow decreases below this threshold level, as occurs during bowel strangulation, regulatory mechanisms are overwhelmed, and oxygen debt ensues. When reperfusion occurs, additional cellular injury contributes both to necrosis as well as extent of recovery. When splanchnic blood flow is restored, as occurs when strangulation is relieved, oxygen extraction increases, providing relatively constant oxygen consumption over a wide range of blood flow rates. Tissues that have experienced irreversible damage will necrose and those that were borderline could recover.

As prolonged ischaemia leads to irreversible tissue necrosis, the main goal of treatment is the prompt restoration of intestinal blood flow. A second-look laparotomy (after $24-48$ hours) is recommended, because the intraoperative assessment of bowel viability is often inaccurate. The rationale for this second look is based in part on the frequent occurrence of vasospasm after revascularisation. This is especially important when the length of healthy bowel is close to the limits required for nutritional viability. ${ }^{12}$

Guidelines for the management of AMI and a position paper on damage control surgery have been published by the World Society of Emergency Surgery. ${ }^{13} 14$ These include immediate fluid resuscitation with correction of electrolyte abnormalities, administration of broad-spectrum antibiotics and prompt laparotomy to re-establish blood supply to ischaemic bowel, resection of non-viable bowel and preservation of all viable bowel. There are no laboratory studies that are sufficiently accurate to identify the presence or the absence of ischaemic or necrotic bowel, although elevated I-lactate and D-dimer may assist (Grade 1B recommendationstrong recommendation with moderate quality evidence-applies to most patients in most circumstances without reservation). CT angiography should be performed as soon as possible for any patient with suspicion of AMI (Grade 1A recommendationapplies to most patients in most circumstances without reservation). Damage control surgery (DCS) is an important adjunct for patients who require intestinal resection due to the necessity to reassess bowel viability and in patients with refractory sepsis, planned re-laparotomy is an essential part of AMI managementthis is a Grade 1B recommendation. Bowel, which is borderline ischaemic at the initial exploration, will improve after restoration of blood supply and physiological stabilisation. Re-exploration should be accomplished within 48 hours and decisions made regarding anastomosis, stoma, resection and abdominal closure. Since the bowel in these patients is often very swollen and at high risk for anastomotic leak, careful hand sewn techniques are preferable to stapled anastomosis. The open abdomen helps reduce the risk of abdominal compartment syndrome in patients requiring prolonged resuscitation. When the surgeon finds massive necrosis of most of the small bowel, he/she is faced with the philosophical question of whether to do anything. Resection of the entire involved bowel will result in short bowel syndrome with its serious associated consequences such as long-term parenteral nutrition and other advanced modes of treatment, which may not be a preferable state-counselling and consent should be obtained to judge whether palliation is the best treatment-this is a Grade 1C recommendation (strong recommendation but subject to change when higher quality evidence becomes available). All these guidelines were followed in our case except for the omission of CT scanning as it was not available.
After a period of 18 hours, it was deemed that further delay could cause worsening acidosis, sepsis and perforation of the ischaemic bowel. The bowel visible through the Bogota bag had not regained normal colour and had become darker over the last 6 hours of observation. At re-laparotomy, it was found that there was a clear demarcation between viable and non-viable bowel and some more bowel had recovered during the time that had elapsed between surgeries. The total length of viable bowel at the second surgery was $100 \mathrm{~cm}$. Resection of non-viable bowel and end-to-end anastomosis was done with interrupted 3-0 polyglactin sutures with cut surfaces having bleeding edges.

Successful complete recovery of advanced bowel ischaemia due to strangulated internal hernia has been reported using damage control surgery with 24 hours and 48 hours of waiting between the first and second surgery. ${ }^{15}$

From a global health perspective, the ideal treatment method in a low-resource setting should use locally available materials and should be affordable to the poor. The total cost of treatment for this patient was Indian rupees (INR) 30164 (equivalent to US\$399.46@ INR 75.51=US\$1). Since the patient could not pay this amount without selling a vital asset, he paid INR 11000 (US\$145.67) and the remaining amount was given as charity.

\section{Patient's perspective}

I was working as a security guard in a city $3500 \mathrm{~km}$ away and had come home for holidays. One morning, I suddenly woke up from my sleep with extreme pain. The pain was so severe that I thought I was going to die. Then I immediately went to the hospital where I was given medication and underwent emergency surgery. Now, 10 months later, I am doing well and able to do all my regular activities without any problem. I am very grateful and thankful for the new life that I have received through the hospital.

\section{Learning points}

- Right paraduodenal hernia (PDH) is a rare cause of intestinal obstruction, which is often diagnosed only during laparotomy, especially when CT scans are not available.

- A 'Bogota bag' can be employed to temporarily close the abdomen while time is given for ischaemic bowel to recover and to observe the bowel through the transparent bag.

- A strangulated PDH with massive bowel ischaemia can be successfully managed with staged surgery and without using parenteral nutrition

Contributors VAI, MK and DPH were involved in the management of the patient. VAl wrote the manuscript. All authors were involved in review of literature, editing the draft and reviewing the manuscript with RY providing anatomical/embryological details and pathophysiology to the discussion.

Funding The authors have not declared a specific grant for this research from any funding agency in the public, commercial or not-for-profit sectors.

Competing interests None declared.

Patient consent for publication Obtained.

Provenance and peer review Not commissioned; externally peer reviewed.

Open access This is an open access article distributed in accordance with the Creative Commons Attribution Non Commercial (CC BY-NC 4.0) license, which permits others to distribute, remix, adapt, build upon this work non-commercially, and license their derivative works on different terms, provided the original work is properly cited and the use is non-commercial. See: http://creativecommons.org/ licenses/by-nc/4.0/. 
ORCID iD

Vijay Anand Ismavel http://orcid.org/0000-0002-2329-596X

\section{REFERENCES}

1 Mehra R, Pujahari AK. Right paraduodenal hernia: report of two cases and review of literature. Gastroenterol Rep 2016;4:168-71.

2 Shadhu K, Ramlagun D, Ping X. Para-duodenal hernia: a report of five cases and review of literature. BMC Surg 2018;18:32.

3 Chiang C-L, Du W-N, Huang S-M, et al. Left Paraduodenal hernia: an uncommon cause of acute abdomen. Int I Gerontol 2011;5:171-2.

4 Ong $M$, Roberts $M$, Perera $M$, et al. Case of a strangulated right paraduodenal fossa hernia in a malrotated gut. BMJ Case Rep 2017;51:bcr-2017-220645.

5 Lin T-P, Liu C-H. Left Paraduodenal hernia with bowel strangulation. Intern Med 2017;56:983-4.

6 Zenitani M, Sasaki T, Tanaka N, et al. Strangulated right paraduodenal hernia successfully treated with single-incision transumbilical surgery. J Pediatr Surg Case Rep 2017:22:1-4

7 Srivastava V, Pandey V, Basu S. Intestinal Ischemia and Gangrene, Gangrene - Current Concepts and Management Options. Alexander Vitin, IntechOpen.

8 Urbanavičius L, Pattyn P, de Putte DV, et al. How to assess intestinal viability during surgery: a review of techniques. World J Gastrointest Surg 2011;3:59.
9 Feliciano DV, Borraez Goana OA. Origin of the Bogota Bag and its Application. In: Damage control in trauma care. Cham: Springer, 2018.

10 Ismavel VA, Thomas G, Zachariah N. Use of plastic material from a urine drainage bag in the staged closure of gastroschisis. Journal of Indian Association of Pediatric Surgeons 4 1999:31-3 https://www.researchgate.net/publication/281792341 Use_of_plastic_material_from_a_urine_drainage_bag_in_the_staged_closure_of_ gastroschisis

11 Messing B, Crenn P, Beau P, et al. Long-Term survival and parenteral nutrition dependence in adult patients with the short bowel syndrome. Gastroenterology 1999;117:1043-50.

12 Endean ED, Barnes SL, Kwolek CJ, et al. Surgical management of thrombotic acute intestinal ischemia. Ann Surg 2001;233:801-8.

13 Bala M, Kashuk J, Moore EE, et al. Acute mesenteric ischemia: guidelines of the world Society of emergency surgery. World J Emerg Surg 2017;12:38

14 Godat L, Kobayashi L, Costantini T, et al. Abdominal damage control surgery and reconstruction: world Society of emergency surgery position paper. World J Emerg Surg 2013:8:53 http://www.wjes.org/content/8/1/53

15 Maselli AM. Strangulated internal herniation with bowel ischemia following abdominoplasty: a case series and review of the literature. Available: https:// www.sages.org/meetings/annual-meeting/abstracts-archive/strangulated-internalherniation-with-bowel-ischemia-following-abdominoplasty-a-case-series-and-reviewof-the-literature/

Copyright 2021 BMJ Publishing Group. All rights reserved. For permission to reuse any of this content visit

https://www.bmj.com/company/products-services/rights-and-licensing/permissions/

BMJ Case Report Fellows may re-use this article for personal use and teaching without any further permission.

Become a Fellow of BMJ Case Reports today and you can:

Submit as many cases as you like

- Enjoy fast sympathetic peer review and rapid publication of accepted articles

Access all the published articles

Re-use any of the published material for personal use and teaching without further permission

Customer Service

If you have any further queries about your subscription, please contact our customer services team on +44 (0) 2071111105 or via email at support@bmj.com.

Visit casereports.bmj.com for more articles like this and to become a Fellow 